\title{
Experimental Test on Glare Composite of an Aircraft Structure Under Tensile Strength Failure
}

\author{
B. Nagaraj Goud, K. Shiva Shankar, B. Manideep, K. Veeranjaneyulu
}

\begin{abstract}
A Glass Aluminum fiber metal laminate GLARE is a set of materials manufactured by strong bonding glass/epoxy layers within the metal layers. The combined set of materials will be providing the better mechanical properties and weight reduction for an aircraft structure. The fiber metal laminate model was fabricated as per ASTM standards $200 \times 30 \times 5 \mathrm{~mm}$ and then the experimental test under tensile loading test was conducted by using universal testing machine UTM as observed the stress-strain curve as the failure strength of GLARE reaching point and finally obtained results. Also to determine the mechanical properties and material characteristics of the unidirectional loading on E-glass fibers used to assemble GLARE for an aircraft structure.
\end{abstract}

Keywords: Fiber metal laminate, mechanical properties, universal testing machine, tensile strength, failure.

\section{INTRODUCTION}

The history of the aerospace industry and aviation, have been conducting intense research work on various types of materials that have been conducted. None of the man made material is flawless or faultless and well as innovative technology progressed, materials would be advanced in terms of safety, the stability of structural material. The latest trend of material like FMLs will be providing the opportunity to use the combined laminate of aluminum with glass/epoxy composite. Aircraft manufacturers from all over the worldwide are incorporating the material in use and evaluating materials performance that can save weight. The significant approach of materials under evaluation for major and minor aircraft structure components are in GLARE laminate, a sandwich material assemble from alternating layers of an aluminum and E- Glass fiber material with the bond layer. According to relevant works of literature, the material takes a joined benefit of the high stiffness and high strength, better yielding properties, better resisting of thermal conducted material and low density form of aluminum panel

Revised Manuscript Received on December 30, 2019.

* Correspondence Author

B. Nagaraj Goud*, Assistant Professor, Department of Aeronautical Engineering, MLR Institute of Technology, Hyderabad (Telangana) India.

E-mail: nagaraj2107@gmail.com

K. Shiva Shankar, Assistant Professor, Department of Aeronautical Engineering, MLR Institute of Technology, Hyderabad (Telangana) India. E-mail: kshiva.shankar02@gmail.com

B. Manideep, Assistant Professor, Department of Aeronautical Engineering, MLR Institute of Technology, Hyderabad (Telangana) India. E-mail: manideepbalusani.9@gmail.com

K. Veeranjaneyulu, Assistant Professor, Department of Aeronautical Engineering, MLR Institute of Technology, Hyderabad (Telangana) India.

(C) The Authors. Published by Blue Eyes Intelligence Engineering and Sciences Publication (BEIESP). This is an open access article under the CC BY-NC-ND license (http://creativecommons.org/licenses/by-nc-nd/4.0/) sheets and the rupture resistance of the glass fibers. The Glare material has good fiber epoxy adhesion, better curing properties, good fatigue properties, simplicity in formability and machinability.

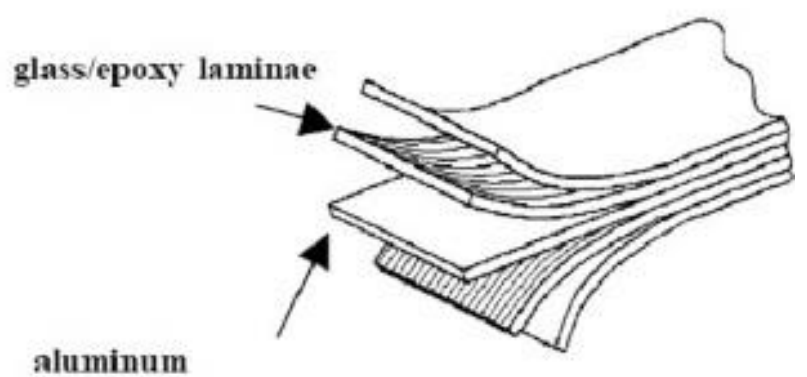

\section{Figure: 1 Glass Laminate Aluminum Reinforced Epoxy GLARE Material}

\section{REVIEW OF LITERATURE}

The reviewed works of a literature study of GLARE composite application in advance aerospace structures domain was extremely focused on the support of research. In the literature the consequence of the volume fraction on the physical properties of fiber/ metallic laminates was explored and its impact in the design properties and performance estimation of aircraft.

The physical properties of Fiber Metal Laminate composites directly depend upon on the mechanical properties and also the various categories of discrete metal and polymer layers (prepregs). Depends on the category and measurable quantity of the suitable materials and the process of layer position (fiber orientation), composites demonstration on different properties (stiffness resistance to shear fatigue resistance, strength,)

In the case of fiber metal laminate, it is essential to identify the material features, the layer considerations and the prepregs that to be estimate the purpose of material properties of the GLARE.

The Metal Volume Fraction (MVF) method is used (Eqn no. 1) for GLARE composite, especially the thickness and the quantity of the Aluminum sheet, which are involved in the metallic stage in the composite.

$\mathrm{Wu}$ and Slagter et al.3 had projected a significance test conducting procedure for material delamination of the fiber/metallic laminates, to study of the bearing stresses with the safe design and calculated the outcome of material behavior property of an edge distance ratio.

$$
\mathrm{MVF}=\frac{\sum_{1}^{P} t_{\text {mil }}}{t_{\text {lasm }}}
$$

In the case of a composite structure applied by the load in the reference parallel to the fiber axis and modulus of elasticity of the composite as calculated in the equation no. 2 . 
Composite material is loaded in the direction at right angles to fiber orientation, the modulus of elasticity was estimated by the equation no. 3

$$
\begin{aligned}
& E_{C}=\left(1-V_{F}\right) E_{m}+V_{f} E_{f}-\cdot-----(2) \\
& E_{C}=\frac{E_{m} V_{f}}{\left(1-V_{F}\right) E_{m}+V_{f} E_{f}}
\end{aligned}
$$

The elastic behavior properties of GLARE was direction dependent and Kawai etal4 conducted elaborate studies on numerous stresses values of GLARE. Viscoelastic material properties and their resistance to the environmental effect upon fibre glass/aluminum laminate epoxy was explored . The GLARE composites materials are prepared by a woven process such as cloth. This woven roving has been made with the coarse fabric in which constant roving the material woven in the direction of two mutually perpendicular. Woven cloth has arranged the fiber using one place over another continuous fiber. That fiber continuous provides biaxial directional properties

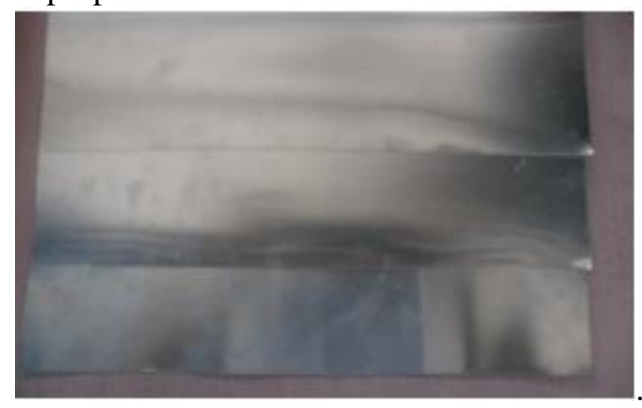

Figure:2 Aluminum sheet

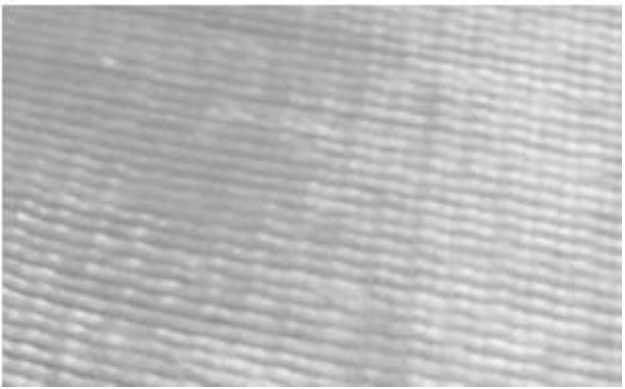

Figure: 3 E-Glass Fiber

The glare fiber provides the strength, fibers glass even tougher when it combines with aluminum sheet material and with these two materials are assembled together with an epoxy resin.

For Airbus, A380 design provides better fuel consumption so GLARE is the perfect combination of high strength to weigh ratio and it is $25 \%$ lighter than aluminum

\section{MATERIAL AND DESIGN SPECIFICATIONS}

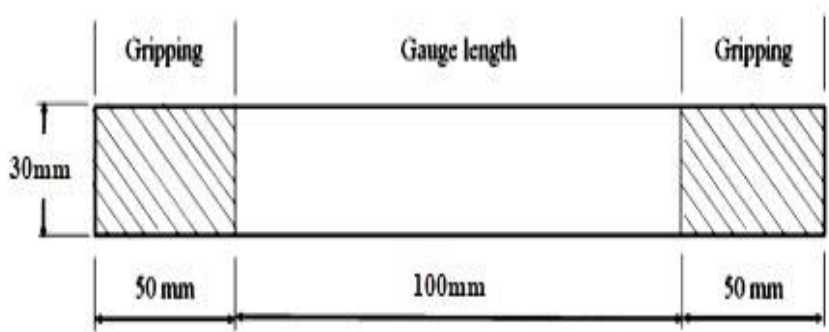

. Figure: 4 GLARE specimen
Table- I: Geometry specification

\begin{tabular}{|c|l|c|c|}
\hline S.No & $\begin{array}{c}\text { Rectangular } \\
\text { laminate }\end{array}$ & $\begin{array}{c}\text { Fiber } \\
\text { orientation: } \\
\mathbf{0}^{\mathbf{0}} \text { angle }\end{array}$ & $\begin{array}{c}\text { Fiber } \\
\text { orientation: } \\
\mathbf{4 5} \text { angle }\end{array}$ \\
\hline 1. & Area & $155.250 \mathrm{~mm}^{2}$ & $120.750 \mathrm{~mm}^{2}$ \\
\hline 2. & Width & $30.5 \mathrm{~mm}$ & $30.5 \mathrm{~mm}$ \\
\hline 3. & $\begin{array}{l}\text { Thickness of } \\
\text { the laminate }\end{array}$ & $4.50 \mathrm{~mm}$ & $3.50 \mathrm{~mm}$ \\
\hline 4. & Gauge Length & $100 \mathrm{~mm}$ & $100 \mathrm{~mm}$ \\
\hline 5. & $\begin{array}{l}\text { Final Gauge } \\
\text { Length }\end{array}$ & $111 \mathrm{~mm}$ & $110 \mathrm{~mm}$ \\
\hline 6. & Final Area & $140 \mathrm{~mm}^{2}$ & $85.25 \mathrm{~mm}^{2}$ \\
\hline
\end{tabular}

\section{EXPERIMENTAL TESTS}

The tensile test was conducted in digitalized servo Universal Testing Machine. The holder was designed in the manner to provide grip at the upper and middle cross heads of the test specimen. The same was done for conducting compressing and bending test.When a material undergoes a uniaxial tensile test where the load is applied through the centroid, fundamental properties such as the stress/strain behavior can be obtained and plotted from the force/deflection response.

A total of two glass/epoxy specimens was tensile tested after tension test. Each metal layer is $0.8 \mathrm{~mm}$ thick

Table- II: Mechanical properties of glass/epoxy and its

\begin{tabular}{|c|c|c|c|c|c|}
\hline $\begin{array}{l}\text { Glass } \\
\text { type }\end{array}$ & $\begin{array}{r}\text { Density } \\
\mathrm{kg} / \mathrm{m}^{3}\end{array}$ & $\begin{array}{c}\text { Poiss } \\
\text { on's } \\
\text { ratio, } \\
1 / \mathrm{m}\end{array}$ & $\begin{array}{c}\text { Modu } \\
\text { lus of } \\
\text { Elasti } \\
\text { city } \\
(\mathrm{GN} / \\
\left.\mathrm{m}^{2}\right)\end{array}$ & $\begin{array}{c}\text { Maximum } \\
\text { Tensile } \\
\text { stresses } \\
\left(\mathrm{MN} / \mathrm{m}^{2}\right)\end{array}$ & $\begin{array}{c}\text { Application } \\
\text { areas }\end{array}$ \\
\hline $\begin{array}{c}\text { E-gla } \\
\text { ss }\end{array}$ & 2550 & 0.22 & $72-80$ & 2000 & $\begin{array}{l}\text { Small } \\
\text { passenger } \\
\text { aircraft } \\
\text { interior } \\
\text { components, } \\
\text { radomes, } \\
\text { solid rocket } \\
\text { casing }\end{array}$ \\
\hline $\begin{array}{l}\text { S-gla } \\
\text { ss }\end{array}$ & 2490 & 0.22 & $85-95$ & 4750 & $\begin{array}{l}\text { Heavy } \\
\text { loaded } \\
\text { components } \\
\text { in thr small } \\
\text { type of } \\
\text { aircrafts. }\end{array}$ \\
\hline $\begin{array}{l}\text { Alum } \\
\text { inium } \\
\text { 2024- } \\
\text { T4 }\end{array}$ & 2780 & 0.33 & $73-80$ & 1950 & $\begin{array}{l}\text { Components } \\
\text { such as skin } \\
\text { of an aircraft, } \\
\text { rocket } \\
\text { casings and } \\
\text { cylinders. }\end{array}$ \\
\hline
\end{tabular}
applications in aerospace 


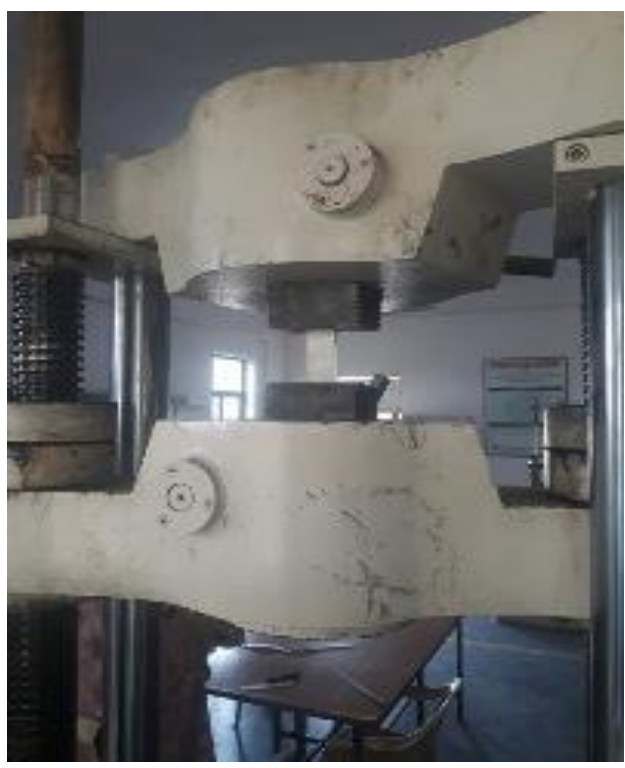

Figure: 5 Tensile failure of a GLARE Specimen in UTM

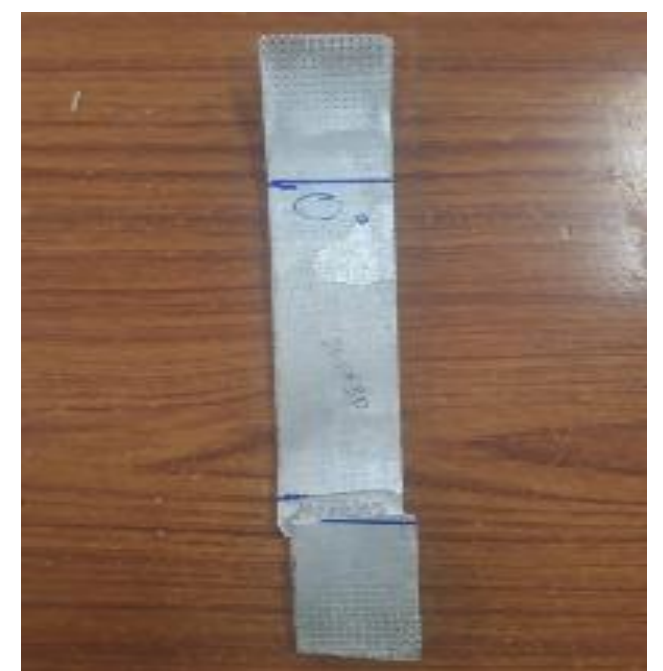

Figure:6 Delimitation of GLARE at 0 degree

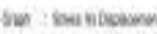

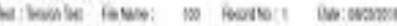

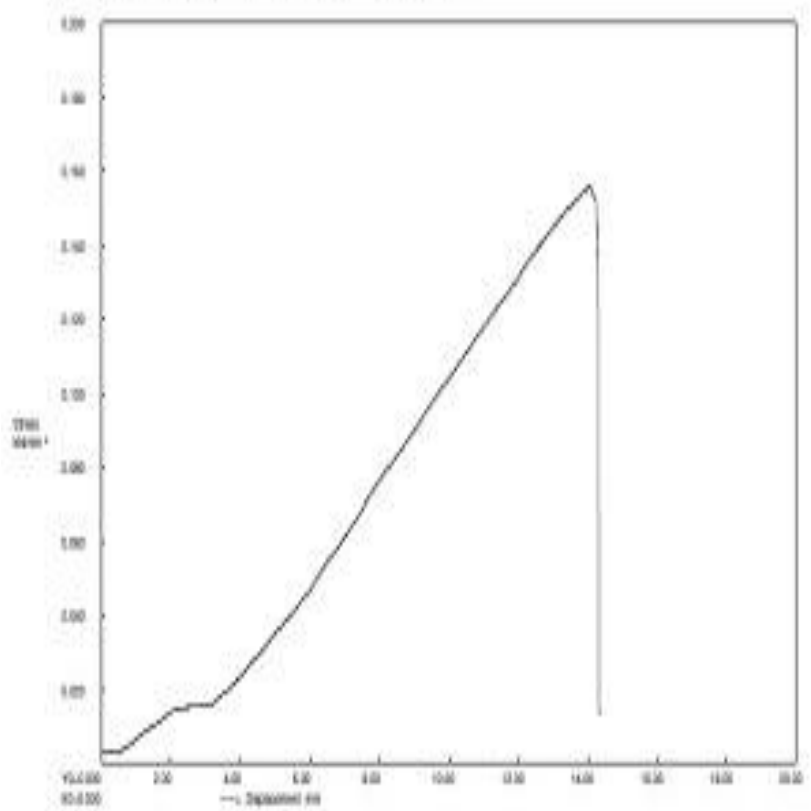

Figure:7 stress vs strain curve

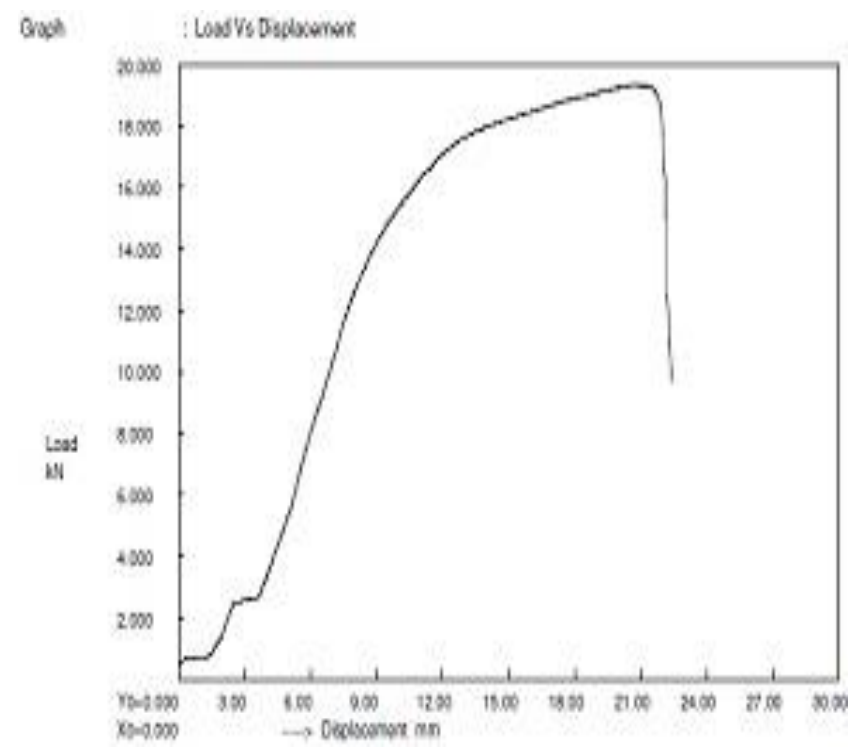

Figure:8 Load vs Displacement Curve

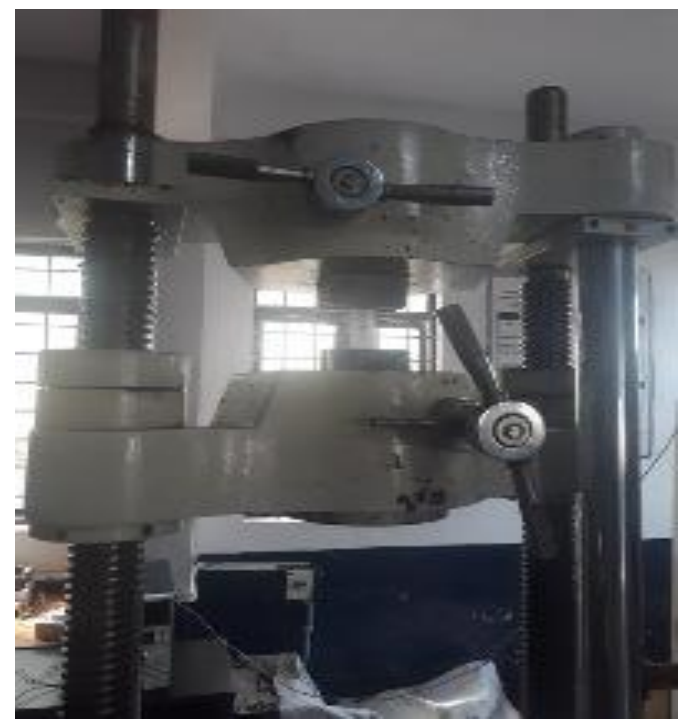

Figure:9 Tensile failure of a GLARE specimen in UTM

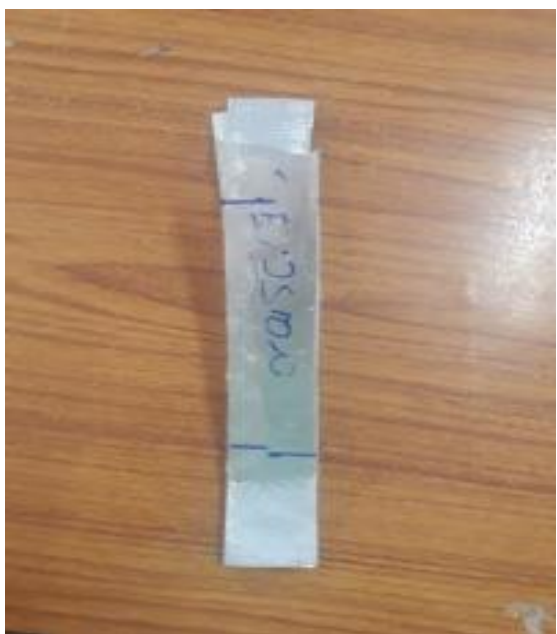

Figure:10 Delamination of GLARE. at 45 degree after tension test.Each metal layer is $0.6 \mathrm{~mm}$ thick

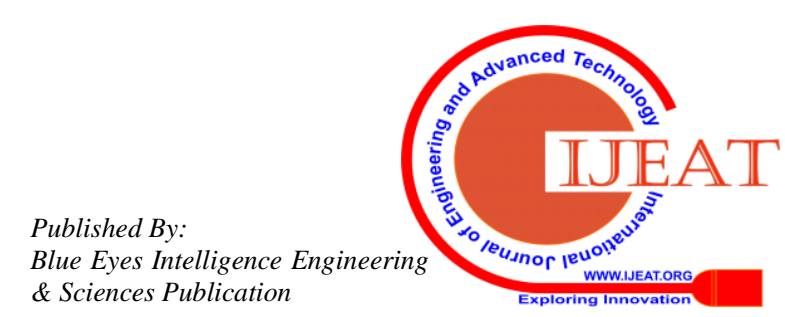




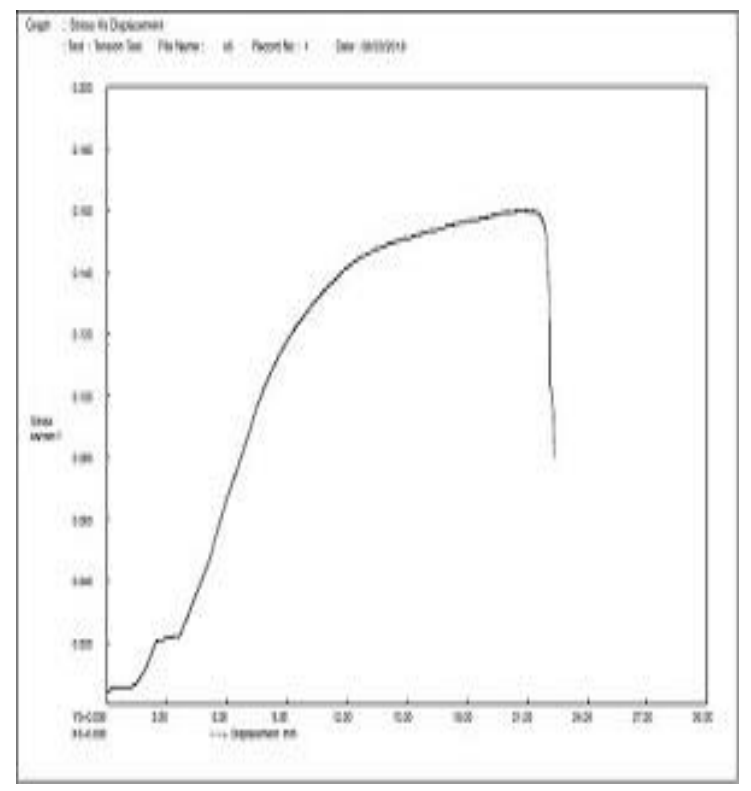

Figure:11 stress vs displacement

\section{EXPERIMENTAL RESULTS}

Table III. Comparison results of Fiber orientation at $0^{0}$ and $45^{\circ}$ angle:

\begin{tabular}{|l|l|l|}
\hline $\begin{array}{l}\text { Failure } \\
\text { parameters }\end{array}$ & $\begin{array}{l}\text { Fiber } \\
\text { orientation: } \\
\mathbf{0}^{\mathbf{0}} \text { angle }\end{array}$ & $\begin{array}{l}\text { Fiber orientation: } \\
\mathbf{4 5}^{\mathbf{0}} \text { angle }\end{array}$ \\
\hline $\begin{array}{l}\text { Maximum Force } \\
(\text { Fm) }\end{array}$ & $19.360 \mathrm{kN}$ & $24.220 \mathrm{kN}$ \\
\hline Disp. at Fm & $20.750 \mathrm{~mm}$ & $14.050 \mathrm{~mm}$ \\
\hline Max. Disp & $22.390 \mathrm{~mm}$ & $14.360 \mathrm{~mm}$ \\
\hline $\begin{array}{l}\text { Tensile Strength } \\
\text { (Rm) }\end{array}$ & $0.160 \mathrm{kN} / \mathrm{mm}^{2}$ & $0.156 \mathrm{kN} / \mathrm{mm}^{2}$ \\
\hline Elongation & $10.000 \%$ & $11.000 \%$ \\
\hline $\begin{array}{l}\text { Reduction in Area } \\
(\mathrm{Z})\end{array}$ & $29.400 \%$ & $9.823 \%$ \\
\hline
\end{tabular}

\section{CONCLUSION}

From the investigation of the fibre metal laminates FMLs had improved more consideration to researchers who perceive exceptional changes in the material improvements in the pure composites. The material layer in the fibre metal laminates leads to changes in complete strength of the entire laminate. The results extracted from our theoretical and experimental studies provide the major mechanical properties of E-glass fiber laminate quantitatively. The GLARE material reinforced and its carried out by the two specimens.

The results obtained from the Universal Testing Machine UTM it is observed that when the GLARE material is reinforced in between the plates, the Ultimate Load of $24.2 \mathrm{kN}$ for $45^{\circ}$ angle fiber orientation is displaced by $14.3 \mathrm{~mm}$ and the Ultimate Tensile Stress by $0.156 \mathrm{kN} / \mathrm{mm}^{2}$. The reinforced composite material engages the strain energy which is responsible for crack propagation along the composite plates leading to structural failure.

\section{REFERENCES}

1. G. H. J. J. Rebooks, "Fiber-metal laminates : Recent developments and applications", Int. Jr. of Fatigue, Vol. 16, 1, January 1994, Pp. 33-42

2. H. F. Wu, L. L. Wu, W. J. Slagter, and J. L. Verolme, "Pilot study of metal volume fraction approach for fiber/metal laminates", Jr. of Aircraft, Vol.32, No.3, 1995, Pp. 663-671

3. H. F. Wu, and W. J. Slagter, , "Parametric studies of bearing strength for fiber/metal laminates", Jr. of Aircraft, Vol. 31, 4, 1994, Pp. 936-945

4. M.Kawai, M. Morishita, S. Tomura and K. Takumida, "Inelastic behavior and strength of fiber-metal hybrid composite: Glare", Int. Jr. of Mechanical Sciences, Vol. 40, 2-3, February-March 1998, Pp. 183-198

5. Abdullah MR., Cantwell WJ., "The mechanical properties of fiber-metal laminates glass fibre reinforced polypropylene", Compos Sci Technol, 60, pp.1085-94, 2000.

6. Johnson WS, Hammond MW, "Crack growth behavior of internal titanium plies of a fiber metal laminate", Composites Part A, 39, pp.1705-15, 2008.

7. Kawai M., Hachinohe A.," Two-stress level fatigue of unidirectional fiber-metal hybrid composite: glare 2" Int J Fatigue, 24, pp.567-80, 2002

8. Asundi A, Choi AYN. Fiber metal laminates: an advanced material for future aircraft. J Mater Proces Technol 1997;63:384-94

9. K Veeranjaneyulu, M S N Gupta, Dhana Jayan Vamsi V Damage Analysis of Low Speed Impact On Composite Materials Internationa Journal of Civil Engineering \& Technology (IJCIET)

10. G. Dhanajayan, Veeranjaneyulu Kalavagunta, V.Vamshi, M.Satyanarana Gupta Environmental Study on GFRP Composite Laminates International Journal of Civil Engineering \& Technology (IJCIET)

11. N K Mishra Dr P K Dash Damage Monitoring of Single Lap Bonded Composite Using Acoustic Emission Technique ICAAMM IOP publishing

\section{AUTHORS PROFILE}

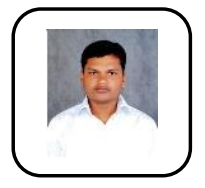

B. Nagaraj Goud, Assistant Professor, in the department of Aeronautical Engineering at MLR Institute of Technology, Hyderabad Telangana and M.Tech in Aerospace Engineering and the Member SAE INDIA Facutly Advisor and professional member from Southern section.

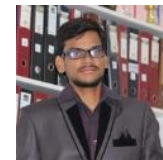

K Shiva Shankar, Assistant Professor, in the department of Aeronautical Engineering at MLR Institute of Technology, Hyderabad Telangana. India.

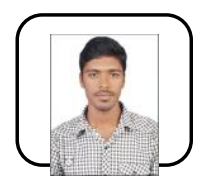

B Manideep, Assistant Professor, in the department of Aeronautical Engineering at MLR Institute of Technology, Hyderabad Telangana. India. 